\title{
Sistemas de manejo na absorção de nitrogênio pelo milho em um Latossolo Vermelho no Cerrado
}

\author{
Cícero Célio de Figueiredo(1), Dimas Vital Siqueira Resck(2), Antonio Carlos Gomes $^{(2)}$ e Segundo Urquiaga ${ }^{(3)}$
}

(1)Universidade de Brasília, Fac. de Agronomia e Medicina Veterinária, Caixa Postal 04508, CEP 70910-970 Brasília, DF. E-mail: ccelio@brturbo.com (2)Embrapa Cerrados, Caixa Postal 08223, CEP 73301-970 Planaltina, DF. E-mail: dvsresck@cpac.embrapa.br (3)Embrapa Agrobiologia, Caixa Postal 74505 CEP 23851-970 Seropédica, DF. E-mail: urquiaga@cnpab.embrapa.br

\begin{abstract}
Resumo - O objetivo deste trabalho foi avaliar o efeito de diferentes sistemas de manejo na absorção de nitrogênio pelo milho em um Latossolo Vermelho no Cerrado. O nitrogênio total $\left(\mathrm{N}_{\text {total }}\right)$, derivado do fertilizante mineral $\left(\mathrm{N}_{\mathrm{dfm}}\right)$ e do solo $\left(\mathrm{N}_{\mathrm{dsolo}}\right)$, foi determinado, além da eficiência de recuperação do nitrogênio fertilizante (ERNF) pelo milho. Os tratamentos foram compostos de oito sistemas de manejo do solo, constituídos de diferentes implementos e épocas de incorporação de restos culturais. O plano de amostragem foi realizado por amostragem aleatória simples. O solo foi a principal fonte de N para as plantas. Sob os sistemas plantio direto ou cultivo mínimo, com escarificação, a cultura do milho apresentou maiores teores de $\mathrm{N} \operatorname{nos}$ grãos $\left(\mathrm{N}_{\text {total }}, \mathrm{N}_{\mathrm{dfm}}\right.$ e $\left.\mathrm{N}_{\mathrm{dsolo}}\right)$, assim como maiores ERNF do que no sistema com duplo revolvimento anual com arado de aivecas. O modo de ação dos arados de discos e de aivecas, bem como a época de incorporação dos restos culturais, pré-plantio e póscolheita, não causaram diferenças nas quantidades de $\mathrm{N}\left(\mathrm{N}_{\text {total }}\right.$ e $\left.\mathrm{N}_{\mathrm{dfm}}\right)$ nos grãos de milho, embora tenham apresentado diferenças nas dinâmicas de absorção destes conforme a época de aplicação.
\end{abstract}

Termos para indexação: ${ }^{15} \mathrm{~N}$, arado de discos, arado de aivecas, plantio direto, escarificador, plantio convencional.

\section{Management systems on nitrogen absorption by corn in an Oxisol in the Cerrado}

\begin{abstract}
The objective of this work was to evaluate the effect of different management systems on nitrogen absorption by corn in an Oxisol in the Cerrado. Total nitrogen $\left(\mathrm{N}_{\text {total }}\right)$, soil and mineral fertilizer derived nitrogen $\left(\mathrm{N}_{\mathrm{dsolo}}\right.$ and $\mathrm{N}_{\mathrm{dfm}}$, respectively), and $\mathrm{N}$-fertilizer recovery efficiency (ERNF) taken by corn were determined. Eight management systems comprised by different implements and crop residues incorporation times were studied. The sampling plan was accomplished by simple random sampling. The soil was the main $\mathrm{N}$ source. Under no-till or minimum tillage, corn grains showed greater $\mathrm{N}$ content $\left(\mathrm{N}_{\text {total }}, \mathrm{N}_{\mathrm{dfm}}\right.$, and $\left.\mathrm{N}_{\mathrm{dsolo}}\right)$, as well as ERNF, than under moldboard plow with crop residues incorporated after harvesting treatment. The disk and moldboard's action plows on soil properties as well as crop residues incorporation time, before planting and after harvesting, did not affect the $\mathrm{N}$ content in the corn grains $\left(\mathrm{N}_{\text {total }}\right.$ and $\left.\mathrm{N}_{\mathrm{dfm}}\right)$, although they presented differences in the absorption dynamics related to $\mathrm{N}$ fertilizer broadcasting periods .
\end{abstract}

Index terms: ${ }^{15} \mathrm{~N}$, disk plow, moldboard plow, no-till, chisel plow, conventional tillage.

\section{Introdução}

Uma série de reações pode ser observada no nitrogênio quando aplicado ao solo. Essas reações podem se estabelecer de diferentes formas, dependendo das propriedades físicas, químicas e microbiológicas do solo. Assim, esse nutriente pode ser lixiviado, volatilizado, absorvido pelas plantas ou imobilizado na biomassa microbiana (Paul \& Clark, 1989).

A maior parte do $\mathrm{N}$ disponível às culturas provém da interação entre dois processos: a fertilização nitrogenada e a mineralização do $\mathrm{N}$ dos resíduos das culturas e do $\mathrm{N}$ da matéria orgânica do solo (Sampaio \& Salcedo, 1993). A principal fonte de $\mathrm{N}$ no solo é a matéria orgânica e a maioria dos solos agrícolas contém várias toneladas de $\mathrm{N}$ orgânico em seus perfis. No entanto, a maior parte desse $\mathrm{N}$ não está disponível para as plantas (Urquiaga \& Zapata, 2000). No Cerrado, os latossolos, que representam $46 \%$ dos solos, apresentam teores de matéria orgânica acima de $26 \mathrm{~g} \mathrm{~kg}^{-1}$, porém de baixa atividade (Resck, 1997). Nesses solos, Kosuge et al. (1994) encontraram variação no teor de $\mathrm{N}$ de 110 a $180 \mathrm{mg}$ de $\mathrm{N}$ por $100 \mathrm{~g}$ de solo na camada de 0 a $15 \mathrm{~cm}$, e de 110 a $150 \mathrm{mg}$ de $\mathrm{N}$ por $100 \mathrm{~g}$ de solo na profundidade de $15 \mathrm{a}$ $30 \mathrm{~cm}$. De acordo com Suhet et al. (1986), esses solos possuem grande capacidade de suprir as plantas com nitrogênio. 
Um aspecto importante é a baixa eficiência de recuperação do $\mathrm{N}$ do fertilizante (ERNF) pelas culturas nessa região. Grove et al. (1980) encontraram ERNF de 50\% pela cultura do milho e Coelho et al. (1991) estudaram o balanço de $\mathrm{N}$, utilizando métodos isotópicos, em um Latossolo Vermelho-Escuro, sob vegetação de Cerrado, cultivado com milho e encontraram que a ERNF foi de $42 \%$ nos grãos e de $57 \%$ na planta toda. Resultados, compilados por Urquiaga (2000), de diversos estudos realizados na América Latina indicam que os mais baixos valores de ERNF pelo milho se apresentaram acompanhados de baixas produtividades.

O uso do isótopo estável ${ }^{15} \mathrm{~N}$ possibilita a diferenciação de fontes nitrogenadas e, com isso, torna mais precisos trabalhos relacionados à ciclagem de $\mathrm{N}$, principalmente em sistemas agrícolas. Na cultura do milho, o uso dessa técnica tem possibilitado a determinação da ERNF em função de diferentes híbridos (Ma \& Dwyer, 1998), da fonte nitrogenada aplicada (Alfaia, 1997), da dose (Kitur et al., 1984), e da forma e época de aplicação de adubos (Lara-Cabezas, 1998). A ERNF pelo trigo, cultivado sob diferentes sistemas de manejo, foi estudada por Power \& Peterson (1998), em solos do Canadá. Nesses estudos, sob o sistema plantio direto, foram verificados os maiores teores de ${ }^{15} \mathrm{~N}$ derivado do fertilizante mineral nas diferentes partes da planta, além do ${ }^{15} \mathrm{~N}$ residual no solo, quando comparado com os sistemas sob cultivo mínimo ou com aração. No entanto, há uma grande carência de estudos que consideram diferentes sistemas de manejo do solo e suas influências no acúmulo de $\mathrm{N}$ e na ERNF pela cultura do milho no Cerrado. Além disso, as dinâmicas das interações de $\mathrm{N}$ do fertilizante com $\mathrm{N}$ nativo do solo são complexas e a influência de diferentes práticas de manejo do solo nessas dinâmicas ainda não é bem entendida (McCarty et al., 1995).

O objetivo deste trabalho foi avaliar o efeito de diferentes sistemas de manejo na absorção de nitrogênio pelo milho em um Latossolo Vermelho no Cerrado.

\section{Material e Métodos}

O trabalho foi conduzido no campo experimental da Embrapa Cerrados, localizado em Planaltina, DF (15035'30"S, 47042'00"W e altitude de $1.014 \mathrm{~m}$ ). O clima da região corresponde ao tipo Aw (tropical chuvoso), segundo classificação de Köppen, com presença de invernos secos e verões chuvosos. Uma característica marcante do clima do Cerrado é um período sem chu- vas dentro da estação chuvosa, conhecido como veranico (Adámoli et al., 1986).

Todos os tratamentos foram instalados em um Latossolo Vermelho argiloso ácido, analisado segundo Embrapa (1997) (Tabela 1). A área experimental corresponde a um experimento de longa duração instalado em 1979, que constitui-se de oito parcelas de $1.250 \mathrm{~m}^{2}$ (Figura 1), com os seguintes tratamentos: 1) ADPP: preparo com arado de discos para incorporação dos resíduos culturais pré-plantio, uma aração anual; 2) ADPC: preparo com arado de discos para incor-

Tabela 1. Caracterização química e física do solo estudado ${ }^{(1)}$.

\begin{tabular}{|c|c|c|c|c|c|}
\hline \multirow[t]{2}{*}{ Atributos } & \multicolumn{5}{|c|}{ Profundidade $(\mathrm{cm})$} \\
\hline & $0-5$ & $5-10$ & $10-20$ & $20-30$ & $30-40$ \\
\hline Corg $\left(\mathrm{g} \mathrm{kg}^{-1}\right)$ & 19 & 18 & 16 & 15 & 12 \\
\hline $\mathrm{pH}\left(\mathrm{H}_{2} \mathrm{O}\right)$ & 5,4 & 5,4 & 5,3 & 5,3 & 5,1 \\
\hline $\mathrm{Al}^{3+}\left(\mathrm{cmol}_{\mathrm{c}} \mathrm{kg}^{-1}\right)$ & 0,1 & 0,1 & 0,3 & 0,3 & 0,6 \\
\hline $\mathrm{H}+\mathrm{Al}\left(\mathrm{cmol}_{\mathrm{c}} \mathrm{kg}^{-1}\right)$ & 5,6 & 5,9 & 6,1 & 6,2 & 6,2 \\
\hline $\mathrm{Ca}^{2+}+\mathrm{Mg}^{2+}\left(\mathrm{cmol}_{\mathrm{c}} \mathrm{kg}^{-1}\right)$ & 5,0 & 4,8 & 4,1 & 3,3 & 1,9 \\
\hline $\mathrm{Ca}^{2+}\left(\mathrm{cmol}_{\mathrm{c}} \mathrm{kg}^{-1}\right)$ & 3,6 & 3,6 & 3,1 & 2,5 & 1,5 \\
\hline $\mathrm{P}\left(\mathrm{mg} \mathrm{kg}^{-1}\right)$ & 9,2 & 11,8 & 8,1 & 3,3 & 1,3 \\
\hline $\mathrm{K}^{+}\left(\mathrm{mg} \mathrm{kg}^{-1}\right)$ & 211 & 113,1 & 50,8 & 34,1 & 22,7 \\
\hline Densidade do solo $\left(\mathrm{Mg} \mathrm{m}^{-3}\right)$ & 1,1 & 1,0 & 1,0 & 1,0 & 1,0 \\
\hline Argila $\left(\mathrm{g} 100 \mathrm{~g}^{-1}\right)$ & 41,0 & 41,2 & 42,2 & 42,1 & 43,0 \\
\hline Silte $\left(\mathrm{g} 100 \mathrm{~g}^{-1}\right)$ & 9,9 & 9,3 & 9,1 & 9,4 & 9,5 \\
\hline Areia $\left(\mathrm{g} 100 \mathrm{~g}^{-1}\right)$ & 49,1 & 49,5 & 48,7 & 48,5 & 47,5 \\
\hline
\end{tabular}

(1) Valores correspondem às médias das amostras de cada profundidade $(\mathrm{n}=24)$.

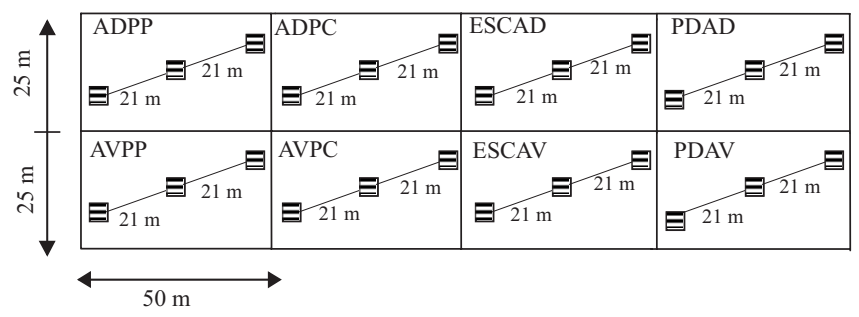

Figura 1. Esquema representativo da área experimental com as microparcelas (口). ADPP: preparo com arado de discos pré plantio; ADPC: preparo com arado de discos pós colheita; ESCAD: preparo com escarificador a partir do segundo ano e arado de discos em 1979, primeiro ano de cultivo; PDAD: plantio direto a partir do segundo ano em área preparada com arado de discos em 1979, primeiro ano de cultivo; AVPP: preparo com arado de aivecas pré plantio; AVPC: preparo com arado de aivecas pós colheita; ESCAV: preparo com escarificador a partir do segundo ano e arado de aivecas em 1979, primeiro ano de cultivo; PDAV: plantio direto a partir do segundo ano em área preparada com arado de aivecas em 1979, primeiro ano de cultivo. 
poração dos resíduos culturais pós-colheita, duas arações anuais; 3) AVPP: preparo com arado de aivecas para incorporação dos resíduos culturais pré-plantio, uma aração anual; 4) AVPC: preparo com arado de aivecas para incorporação dos resíduos culturais pós-colheita, duas arações anuais; 5) ESCAD: preparo com escarificador a partir do segundo ano e arado de discos em 1979, primeiro ano de cultivo; 6) ESCAV: preparo com escarificador a partir do segundo ano e arado de aivecas em 1979, primeiro ano de cultivo; 7) PDAD: plantio direto a partir do segundo ano em área preparada com arado de discos em 1979, primeiro ano de cultivo; 8) PDAV: plantio direto a partir do segundo ano em área preparada com arado de aivecas em 1979, primeiro ano de cultivo.

Neste experimento são, portanto, analisadas diferentes épocas de incorporação de restos culturais - antes do plantio e após a colheita -, a ação de diferentes implementos utilizados nas operações de preparo do solo e as alterações deixadas por estes implementos na adoção do plantio direto nestas áreas. Toda a área experimental era vegetada por pastagens naturais antes da implantação do experimento, ou seja, sem uso agrícola.

O milho cultivar BR 205 foi semeado em 16 de novembro de 2001 manualmente. A adubação de plantio, comum a todos os tratamentos, foi de $500 \mathrm{~kg} \mathrm{ha}^{-1} \mathrm{da}$ fórmula 0-20-20, mais $48 \mathrm{~kg} \mathrm{ha}^{-1}$ de FTE BR-12. A adubação nitrogenada foi feita com sulfato de amônio na dose de $90 \mathrm{~kg} \mathrm{ha}^{-1}$ de $\mathrm{N}$, parcelada em três épocas ( $30 \mathrm{~kg} \mathrm{ha}^{-1}$ de $\mathrm{N}$ por vez): no plantio e aos 20 e 45 dias após o plantio (DAP), quando as plantas apresentavam de 4 a 6 e de 8 a 10 folhas, respectivamente, baseada na expectativa de produção de grãos. A colheita foi realizada, manualmente, em 19 de abril de 2002. Em cada parcela foram demarcadas três microparcelas eqüidistantes, utilizando-se três linhas de $2 \mathrm{~m}$ cada, obedecendo ao espaçamento da cultura de $0,90 \mathrm{~m}$ entrelinhas. As linhas das microparcelas receberam sulfato de amônio marcado com 2,5\% de átomos de ${ }^{15} \mathrm{~N}$ em excesso, em três épocas diferentes, da seguinte forma: linha 1,30 $\mathrm{kg} \mathrm{ha}^{-1}$ de $\mathrm{N}$ no plantio; linha 2,30 $\mathrm{kg} \mathrm{ha}^{-1} \mathrm{de}$ $\mathrm{N}$ aos 20 DAP; linha 3,30 $\mathrm{kg} \mathrm{ha}^{-1}$ de $\mathrm{N}$ aos 45 DAP.

As análises foram realizadas utilizando-se grãos colhidos em cinco plantas de cada microparcela em 19 de abril de 2002, com teor médio de água de $14 \%$. As determinações de nitrogênio total $\left(\mathrm{N}_{\text {total }}\right)$ nas amostras de grãos foram realizadas por colorimetria, a partir do extrato de digestão com ácido perclórico e peróxido de hidrogênio, de acordo com Oliveira (1981), com adapta- ções. A composição isotópica do ${ }^{15} \mathrm{~N}$ foi analisada em espectrômetro de massa Delta Plus, Finnigan, UK, na Embrapa Agrobiologia, Seropédica, RJ.

$\mathrm{Na}$ determinação do $\mathrm{N}$ derivado do fertilizante mineral $\left(\mathrm{N}_{\mathrm{dfm}}\right)$, em kg ha ${ }^{-1}$, nos grãos de milho, utilizou-se a expressão:

$\mathrm{N}_{\mathrm{dfm}}\left(\mathrm{kg} \mathrm{ha}^{-1}\right)=\left(\frac{\% \text { átomos }{ }^{15} \mathrm{~N} \text { em excesso no grão }}{\% \text { átomos }{ }^{15} \mathrm{~N} \text { em excesso no fertilizan te }}\right)$ $\times \mathrm{N}_{\text {total }}$ na MS do grão

em que MS do grão é a matéria seca de grãos em $\mathrm{kg} \mathrm{ha}^{-1}$.

$\mathrm{Na}$ determinação do $\mathrm{N}$ derivado do solo $\left(\mathrm{N}_{\mathrm{dsolo}}\right)$, foi considerado todo o $\mathrm{N}$ no grão que não era oriundo do fertilizante mineral marcado, desconsiderando-se, portanto, todas as outras possíveis formas de absorção desse nutriente. A sua determinação obedeceu à seguinte expressão:

$\mathrm{N}_{\text {dsolo }}\left(\mathrm{kg} \mathrm{ha}^{-1}\right)=\left(1-\mathrm{N}_{\mathrm{dfm}}\right) \times \mathrm{N}_{\text {total }}$ na matéria seca de grão em $\mathrm{kg} \mathrm{ha}^{-1}$.

A eficiência de recuperação do $\mathrm{N}$ do fertilizante (ERNF) pelo grão é verificada na quantidade de $\mathrm{N}$ recuperado pelos grãos em relação à quantidade de $\mathrm{N}$ fertilizante aplicado. Na sua determinação utilizou-se a seguinte expressão:

ERNF $(\%)=\left(\frac{\mathrm{N}_{\mathrm{dfm}}}{30 \mathrm{~kg} \mathrm{ha}^{-1} \text { de N-fertilizante aplicado como adubo }}\right) \times 100$

O teste não-paramétrico de Wilcoxon (Campos, 1979) foi usado nas análises das médias submetidas a uma ordem de classificação do $\mathrm{N}_{\text {total }}, \mathrm{N}_{\mathrm{dfm}}, \mathrm{N}_{\mathrm{dsolo}}$ e ERNF.

Utilizou-se o teste F multivariado na comparação de modelos de regressão não-ortogonal, $Y=b_{0}+b_{1} x+b_{2} x^{2}+b_{3} x^{3}$, para as variáveis $\mathrm{N}_{\mathrm{dfm}}, \mathrm{N}_{\mathrm{dsolo}}$ e ERNF em todos os tratamentos, em que $b_{0}, b_{1}, b_{2}$ e $b_{3}$ representam os parâmetros para o intercepto, linear, quadrático e cúbico, respectivamente.

\section{Resultados e Discussão}

Considerando-se a dose de $\mathrm{N}$ fertilizante aplicada total (90 $\mathrm{kg} \mathrm{ha}^{-1} \mathrm{de} \mathrm{N}$ ), a ERNF pelos grãos variou de $26 \%$ no AVPC a 34\% no ESCAV (Figura 2). Esses resultados equivalem aos freqüentemente encontrados na literatura, embora haja valores bem diferenciados, principalmente por causa da grande variação nas áreas e nas condições experimentais. No Cerrado, em um Latossolo Vermelho-Escuro, Coelho et al. (1991) encontraram ERNF média nos grãos de milho de $42 \%$. Jokela \& Randall (1997) constataram valores baixos, de $13 \%$ a $32 \%$, até $60 \%$, dependendo das doses de fertilizantes 
aplicadas. Kitur et al. (1984) verificaram uma variação de $23 \%$ a $48 \%$ nessa taxa, em solos sob diferentes sistemas de manejo. De acordo com Urquiaga \& Zapata (2000b), em um ciclo de cultivo, a ERNF dificilmente supera os $50 \%$.

Os sistemas ESCAV e PDAV apresentaram maiores ERNF, 34\% e 33\%, respectivamente, do que o sistema AVPC, 26\%. Estes, entretanto, não diferiram dos demais sistemas (Figura 2). Esses resultados demonstram que o uso do arado de aivecas que é utilizado na incorporação de carbono dos restos culturais em préplantio (AVPP) no perfil e na melhoria da estrutura do solo, nos primeiros anos de cultivo, antes do estabelecimento do plantio direto ou do uso do escarificador, proporcionou condições adequadas para uma boa eficiência na utilização do $\mathrm{N}$ do fertilizante. Entretanto, com o uso contínuo desse implemento, com duplo revolvimento anual do solo, isso não acontece.

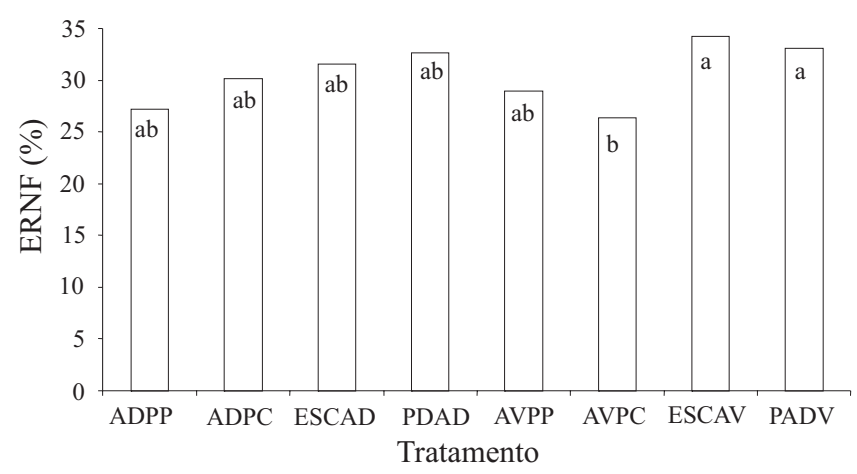

Figura 2. Eficiência de recuperação do nitrogênio do fertilizante (ERNF) pelos grãos de milho sob oito sistemas de manejo do solo, com comparação de médias pelo teste t a $5 \%$ de significância correspondente ao teste de Wilcoxon, aplicado à ordem de classificação, a partir dos dados originais. ADPP: preparo com arado de discos pré-plantio; ADPC: preparo com arado de discos pós-colheita; ESCAD: preparo com escarificador a partir do segundo ano e arado de discos em 1979, primeiro ano de cultivo; PDAD: plantio direto a partir do segundo ano em área preparada com arado de discos em 1979, primeiro ano de cultivo; AVPP: preparo com arado de aivecas pré-plantio; AVPC: preparo com arado de aivecas pós-colheita; ESCAV: preparo com escarificador a partir do segundo ano e arado de aivecas em 1979, primeiro ano de cultivo; PDAV: plantio direto a partir do segundo ano em área preparada com arado de aivecas em 1979, primeiro ano de cultivo.
Segundo Power \& Peterson (1998), na colheita do trigo, em solos sob diferentes sistemas de manejo, as maiores taxas de recuperação de $\mathrm{N}$ do fertilizante, no somatório das diferentes partes da planta, grãos mais palha, mais o residual no solo, foram encontradas no plantio direto, por causa da mais lenta reciclagem do $\mathrm{N}$ do fertilizante neste tratamento.

O sistema PDAV apresentou um modelo quadrático para ERNF diferente dos demais, com menor ERNF aos $23 \mathrm{DAP}$, próximo à primeira adubação de cobertura (20 DAP) (Figura 3). O tratamento PDAD apresentou ERNF com tendência linear e crescente. Isso demonstra uma dinâmica diferenciada na ERNF entre esses dois sistemas, provavelmente ocasionada pela ação dos arados de discos e de aivecas que permanece mesmo após 22 anos sob plantio direto. Essa constatação reforça a necessidade de se estudar os sistemas de manejo do solo sob uma perspectiva dinâmica (Resck, 1997), no sentido de que todo implemento tem sua época de utilização devido às suas características e modos de ação para atingir determinados objetivos, como a correção química e melhoria das propriedades físicas do solo.

Enquanto sob os sistemas ESCAV, ADPC, ESCAD e AVPP as maiores ERNF foram obtidas próximo à primeira adubação de cobertura $(22,23,26$ e 28 DAP, respectivamente), sob o PDAV o comportamento foi exatamente o oposto. O modelo de regressão em relação ao ESCAV não foi significativo. Esses modelos possibilitam informar quais as épocas mais adequadas para a aplicação do fertilizante nos diferentes sistemas, visando a melhor utilização pelas plantas. Assim, sob o tratamento PDAV, a primeira aplicação do adubo nitrogenado teria que ser feita no plantio, a segunda aos 10 dias, e a terceira, 40 dias após o plantio. No tratamento PDAD, para atingir ERNF igual a 38\% (máximo valor do PDAV), seriam necessários 38 dias após o plantio para a recuperação do $\mathrm{N}$ pelo milho. $\mathrm{O}$ sistema PDAV apresentou um modelo para ERNF diferente dos demais tratamentos, com exceção do ESCAV (Tabela 2). Isso demonstra que há uma dinâmica diferenciada na ERNF pelo milho nesse sistema.

O sistema PDAD apresentou um modelo para ERNF diferente dos sistemas ADPC e ESCAV, além do PDAV. Essas diferenças entre as dinâmicas de utilização do $\mathrm{N}$ 

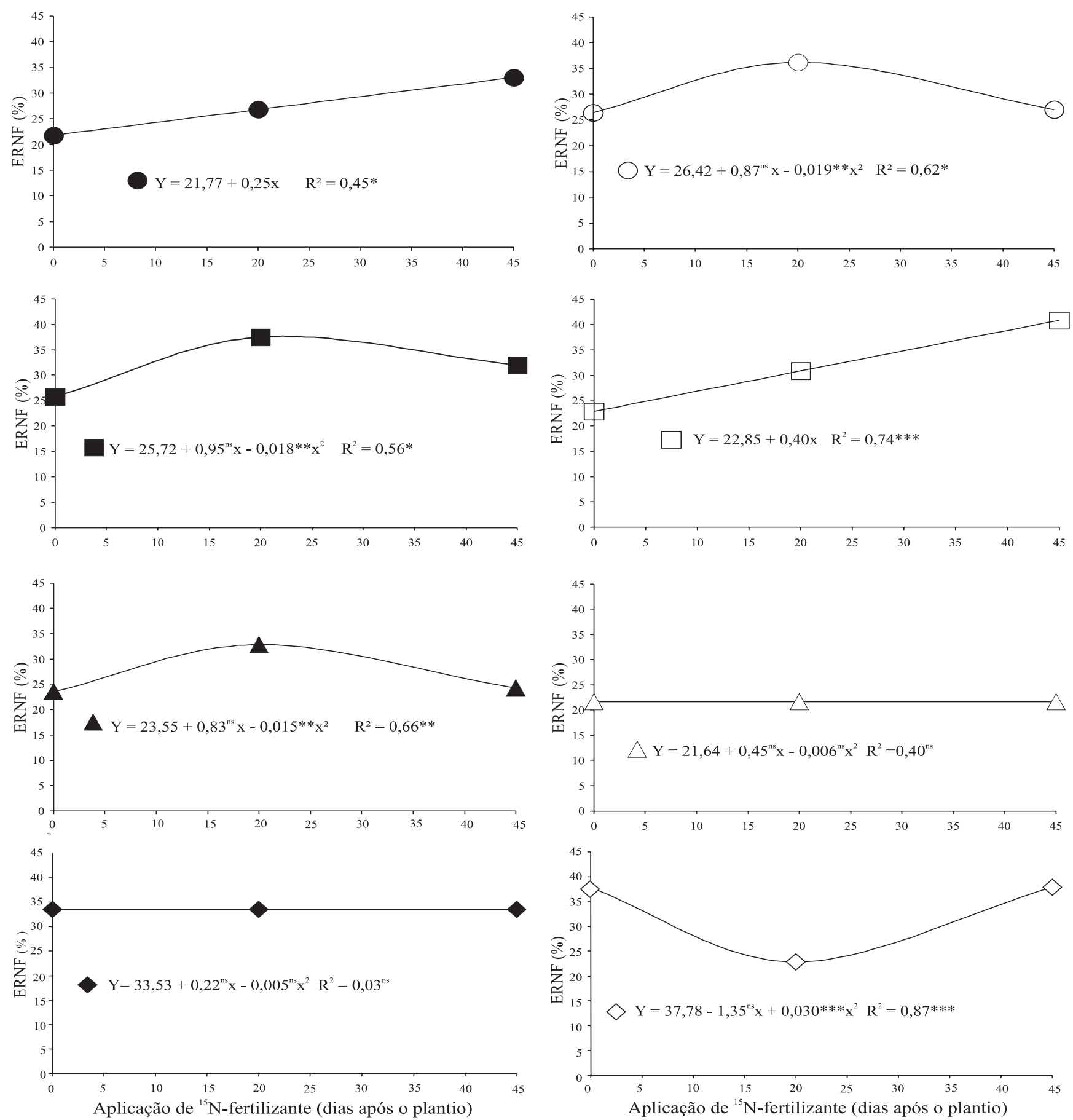

Figura 3. Modelos da eficiência de recuperação do nitrogênio do fertilizante (ERNF) pelo grão de milho em oito sistemas de manejo em diferentes épocas de aplicação de ${ }^{15} \mathrm{~N}$-fertilizante. $\mathrm{ADPP}(\mathbf{O})$ : preparo com arado de discos pré-plantio; $\mathrm{ADPC}(\mathrm{O})$ : preparo com arado de discos pós-colheita; ESCAD ( $\boldsymbol{\square})$ : preparo com escarificador a partir do segundo ano e arado de discos em 1979, primeiro ano de cultivo; PDAD $(\square)$ : plantio direto a partir do segundo ano em área preparada com arado de discos em 1979, primeiro ano de cultivo; $\operatorname{AVPP}(\boldsymbol{\Delta})$ : preparo com arado de aivecas pré-plantio; AVPC $(\triangle)$ : preparo com arado de aivecas pós-colheita; ESCAV $(\diamond)$ : preparo com escarificador a partir do segundo ano e arado de aivecas em 1979, primeiro ano de cultivo; PDAV $(\diamond)$ : plantio direto a partir do segundo ano em área preparada com arado de aivecas em 1979, primeiro ano de cultivo. ns Não-significativo. ${ }^{*},{ }^{* *} \mathrm{e}^{* * *}$ Significativo a $10 \%$, a $5 \%$ e a $1 \%$ de probabilidade, respectivamente. 
fertilizante encontradas para os sistemas sob plantio direto indicam que o revolvimento realizado pelos arados de discos e de aivecas, para a correção química do solo, no primeiro ano do experimento, proporcionou um ambiente diferenciado nesses sistemas, que ainda permanece após todos esses anos.

Observou-se ausência de diferenças (valores de F não-significativos) entre os modelos para ERNF nos diferentes sistemas que sofreram algum tipo de revolvimento, indicando que os revolvimentos, sejam eles com uma ou duas incorporações anuais dos resíduos culturais, estabeleceram dinâmicas semelhantes na eficiência de utilização do $\mathrm{N}$ do fertilizante.

Os valores de $\mathrm{N}_{\mathrm{dfm}}$ em kg ha-1, considerando a dose total de $\mathrm{N}$ aplicada $\left(90 \mathrm{~kg} \mathrm{ha}^{-1} \mathrm{de} \mathrm{N}\right)$, apresentaram variações de 24 a $31 \mathrm{~kg} \mathrm{ha}^{-1}$ (Figura 4). O tratamento $\operatorname{ESCAV~}\left(31 \mathrm{~kg} \mathrm{ha}^{-1}\right)$ apresentou $\mathrm{N}_{\mathrm{dfm}}$ nos grãos superior aos tratamentos ADPP e AVPC (25 e $24 \mathrm{~kg} \mathrm{ha}^{-1}$, respectivamente). Houve também diferença significativa entre o PDAV $\left(28 \mathrm{~kg} \mathrm{ha}^{-1}\right)$ e o AVPC $\left(24 \mathrm{~kg} \mathrm{ha}^{-1}\right)$. Os demais tratamentos não diferiram significativamente entre si. Os valores de $\mathrm{N}_{\mathrm{dfm}}$ são semelhantes aos encontrados por Coelho et al. (1991), cuja quantidade de $\mathrm{N}_{\mathrm{dfm}}$ em grãos de milho, média de dois métodos de aplicação de uréia, foi de $25 \mathrm{~kg} \mathrm{ha}^{-1}$.

Kitur et al. (1984) mostraram que, no sistema plantio direto, há necessidade de doses maiores de $\mathrm{N}$ para que o milho apresente maiores teores desse nutriente nos grãos, em comparação ao cultivo com preparo conven- cional do solo, justificada pelas taxas mais lentas de mineralização e maiores taxas de imobilização e desnitrificação no primeiro sistema.

Sob o sistema ESCAD, o milho apresentou maior quantidade de $\mathrm{N}_{\text {dsolo }}\left(77 \mathrm{~kg} \mathrm{ha}^{-1}\right)$ no grão do que sob o AVPC (55 kg ha-1) (Figura 4). Não houve diferenças entre os outros tratamentos. Os valores de $\mathrm{N}_{\mathrm{dsolo}}$ nos diferentes sistemas seguiram o mesmo padrão encontrado para o $\mathrm{N}_{\text {total, }}$, ambos nos grãos, o que mostra a predominância da contribuição do Latossolo no acúmulo de N nos grãos de milho. Mesmo não havendo diferença entre os sistemas ESCAD e AVPC com relação a ERNF (Figura 2), a contribuição do solo no ESCAD para o $\mathrm{N}$ total nos grãos foi maior do que no AVPC e, conseqüentemente, o sistema ESCAD produziu $830 \mathrm{~kg} \mathrm{ha}^{-1}$ de matéria seca de grãos a mais do que no AVPC (Tabela 3 ).

Nos solos do Cerrado que apresentam matéria orgânica de baixa atividade, segundo Resck (1997), o sistema com escarificador, que causa um mínimo revolvimento do solo, e pode atingir $45 \mathrm{~cm}$ de profundidade, rompendo camadas adensadas e compactadas do solo, apresenta-se como uma alternativa viável ao sistema de plantio direto para contornar as limitações químicas e físicas desses solos e aumentar as produtividades das culturas, com melhor aproveitamento dos fertilizantes nitrogenados, evitando perdas e poluição do meio ambiente. Por outro lado, o duplo revolvimento anual do solo para incorporação dos restos culturais utilizando o arado de aivecas (AVPC) proporcionou as menores

Tabela 2. Valores de F multivariado para comparação dos parâmetros da regressão dos tratamentos em relação à eficiência de recuperação de nitrogênio do fertilizante dos oito sistemas de manejo.

\begin{tabular}{|c|c|c|c|c|c|c|c|}
\hline \multirow[t]{2}{*}{ Tratamento $^{(1)}$} & \multicolumn{7}{|c|}{ Valores de F multivariado } \\
\hline & ADPP & ADPC & ESCAD & PDAD & AVPP & AVPC & ESCAV \\
\hline ADPC & $2,08^{\mathrm{ns}}$ & & & & & & \\
\hline ESCAD & $2,48^{\mathrm{ns}}$ & $0,21^{\mathrm{ns}}$ & & & & & \\
\hline PDAD & $2,42^{\mathrm{ns}}$ & $14,39^{* * *}$ & $2,75^{\mathrm{ns}}$ & & & & \\
\hline AVPP & $0,85^{\mathrm{ns}}$ & $0,68^{\mathrm{ns}}$ & $0,06^{\mathrm{ns}}$ & $3,24^{\mathrm{ns}}$ & & & \\
\hline AVPC & $0,41^{\text {ns }}$ & $1,08^{\mathrm{ns}}$ & $1,60^{\text {ns }}$ & $1,18^{\mathrm{ns}}$ & $0,42^{\mathrm{ns}}$ & & \\
\hline ESCAV & $0,82^{\text {ns }}$ & $1,66^{\mathrm{ns}}$ & $0,40^{\mathrm{ns}}$ & $4,72^{*}$ & $0,54^{\mathrm{ns}}$ & $0,32^{\mathrm{ns}}$ & \\
\hline PDAV & $16,57^{* * *}$ & $12,50^{* * *}$ & $45,90^{* * *}$ & $12,86^{* *}$ & $22,96^{* * *}$ & $8,61^{* *}$ & $2,93^{\mathrm{ns}}$ \\
\hline
\end{tabular}

(1)ADPP: preparo com arado de discos pré-plantio; ADPC: preparo com arado de discos pós-colheita; ESCAD: preparo com escarificador a partir do segundo ano e arado de discos em 1979, primeiro ano de cultivo; PDAD: plantio direto a partir do segundo ano em área preparada com arado de discos em 1979, primeiro ano de cultivo; AVPP: preparo com arado de aivecas pré-plantio; AVPC: preparo com arado de aivecas pós-colheita; ESCAV: preparo com escarificador a partir do segundo ano e arado de aivecas em 1979, primeiro ano de cultivo; PDAV: plantio direto a partir do segundo ano em área preparada com arado de aivecas em 1979, primeiro ano de cultivo. ns Não-significativo.*, ** e ***Significativo a $10 \%$, a $5 \%$ e a $1 \%$, de probabilidade, respectivamente. 


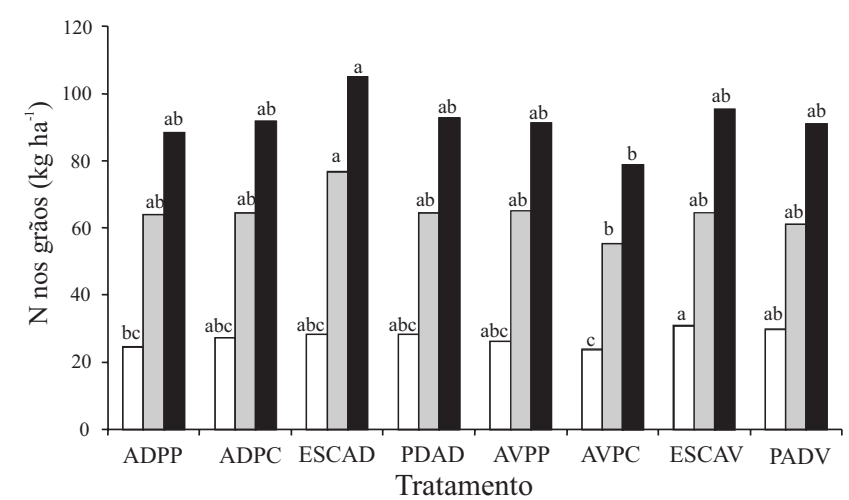

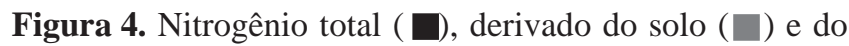
fertilizante mineral $(\square)$ em grãos de milho sob oito sistemas de manejo do solo, após a aplicação total do nitrogênio (90 $\mathrm{kg} \mathrm{ha}^{-1}$ ), com comparação de médias pelo teste $\mathrm{t}$ a $5 \%$ de significância correspondente ao teste de Wilcoxon, aplicado à ordem de classificação, a partir dos dados originais. Tratamentos com letras iguais, dentro da mesma variável, não diferem entre si pelo teste t. ADPP: preparo com arado de discos pré-plantio; ADPC: preparo com arado de discos pós-colheita; ESCAD: preparo com escarificador a partir do segundo ano e arado de discos em 1979, primeiro ano de cultivo; PDAD: plantio direto a partir do segundo ano em área preparada com arado de discos em 1979, primeiro ano de cultivo; AVPP: preparo com arado de aivecas pré-plantio; AVPC: preparo com arado de aivecas pós-colheita; ESCAV: preparo com escarificador a partir do segundo ano e arado de aivecas em 1979, primeiro ano de cultivo; PDAV: plantio direto a partir do segundo ano em área preparada com arado de aivecas em 1979, primeiro ano de cultivo.

Tabela 3. Produtividade do milho em oito sistemas de manejo.

\begin{tabular}{cc}
\hline Tratamento $^{(1)}$ & Grãos $\left(\mathrm{kg} \mathrm{ha}^{-1}\right)$ \\
\hline ADPP & $6.890^{\mathrm{ns}}$ \\
ADPC & $7.132^{\mathrm{ns}}$ \\
ESCAD & $7.449^{\mathrm{ns}}$ \\
PDAD & $7.281^{\mathrm{ns}}$ \\
AVPP & $7.044^{\mathrm{ns}}$ \\
AVPC & $6.621^{\mathrm{ns}}$ \\
ESCAV & $7.170^{\mathrm{ns}}$ \\
PDAV & $6.950^{\mathrm{ns}}$ \\
\hline
\end{tabular}

(1)ADPP: preparo com arado de discos pré-plantio; ADPC: preparo com arado de discos pós-colheita; ESCAD: preparo com escarificador a partir do segundo ano e arado de discos em 1979, primeiro ano de cultivo; PDAD: plantio direto a partir do segundo ano em área preparada com arado de discos em 1979, primeiro ano de cultivo; AVPP: preparo com arado de aivecas pré-plantio; AVPC: preparo com arado de aivecas pós-colheita; ESCAV: preparo com escarificador a partir do segundo ano e arado de aivecas em 1979, primeiro ano de cultivo; PDAV: plantio direto a partir do segundo ano em área preparada com arado de aivecas em 1979, primeiro ano de cultivo. ${ }^{\text {ns Não-significativo }}$ a $5 \%$ de probabilidade pelo teste $\mathrm{F}$. quantidades de $\mathrm{N}$ nos grãos, além de baixa eficiência de recuperação do $\mathrm{N}$ do fertilizante (Figura 4). Esses resultados possibilitam inferir que, nas condições edafoclimáticas do Cerrado, a dupla incorporação dos restos culturais com arado de aivecas, no início da estação seca e no início das chuvas, outubro e novembro, diminui os teores de $\mathrm{N}$ no solo e, conseqüentemente, o aproveitamento deste pela cultura do milho. Entretanto, estudos adicionais sobre o comportamento do $\mathrm{N}$ do solo, sob diferentes manejos no Cerrado, precisam ser realizados.

$\mathrm{O}$ sistema ADPC apresentou maior absorção de $\mathrm{N}_{\mathrm{dsolo}}$ linear e decrescente, conforme a época de adubação, com maior quantidade de $\mathrm{N}_{\text {dsolo }}$ no plantio, diminuindo com as adubações subseqüentes (Figura 5). Nos sistemas ESCAV e PDAV esta absorção seguiu um modelo quadrático com as menores quantidades encontradas próximo à primeira adubação de cobertura, mais precisamente aos 23 DAP.

Em todas as variáveis analisadas $\left(\mathrm{N}_{\mathrm{dfm}}, \mathrm{N}_{\mathrm{dsolo}} \mathrm{e}\right.$ ERNF), o sistema sob plantio direto (PDAV) apresentou os menores valores de $\mathrm{N}_{\text {dsolo }}$ absorvidos próximo à primeira adubação de cobertura, com aumento a partir deste ponto.

Segundo Sá (1998), nos sistemas sob plantio direto ocorrem, em alguns períodos, picos com maior imobilização pela biomassa microbiana do solo e, na seqüência, picos com maior mineralização, disponibilizando $\mathrm{N}$ para as plantas. Nesse sistema, a liberação de $\mathrm{N}$ após o período de imobilização provavelmente coincide com o início do florescimento, momento em que ocorre elevada utilização de $\mathrm{N}$ pela cultura do milho.

As curvas de crescimento dos valores observados de $\mathrm{N}$ derivado do fertilizante mineral $\left(\mathrm{N}_{\mathrm{dfm}}\right)$, de forma linear para PDAD, e quadrática, com elevação a partir dos 20 DAP para o PDAV, encontrados para ERNF e podendo culminar com maiores teores absorvidos na floração, comprovam esse fato (Figura 3).

Neste trabalho, a ERNF foi média, mas as produtividades foram altas, em média, $7.065 \mathrm{~kg} \mathrm{ha}^{-1}$ de grãos, indicando que o solo tinha boa disponibilidade de N, constituindo-se na principal fonte deste nutriente para a cultura (Tabela 3). Em conseqüência, o $\mathrm{N}$ do fertilizante aplicado diluiu-se com o $\mathrm{N}$ disponível nativo do solo, diminuindo sua disponibilidade relativa para a planta (Urquiaga, 2000). 

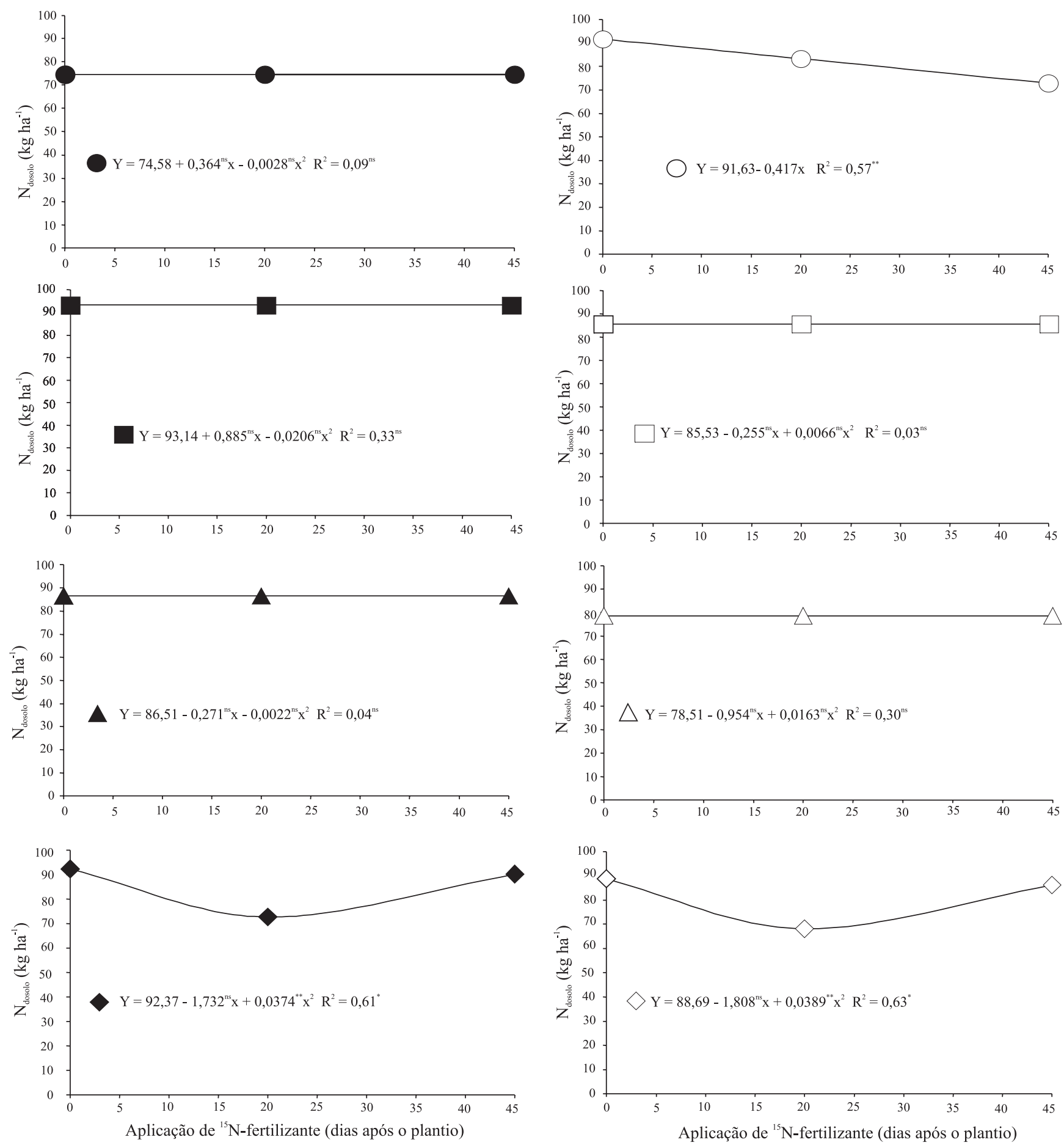

Figura 5. Comportamento do nitrogênio derivado do solo em grãos de milho sob oito sistemas de manejo em diferentes épocas de aplicação de ${ }^{15} \mathrm{~N}$-fertilizante. ADPP (O): preparo com arado de discos pré-plantio; ADPC (O): preparo com arado de discos pós-colheita; ESCAD ( $\square$ ): preparo com escarificador a partir do segundo ano e arado de discos em 1979, primeiro ano de cultivo; PDAD ( $\square$ ): plantio direto a partir do segundo ano em área preparada com arado de discos em 1979, primeiro ano de cultivo; $\operatorname{AVPP}(\boldsymbol{\Delta})$ : preparo com arado de aivecas pré-plantio; AVPC $(\triangle)$ : preparo com arado de aivecas pós-colheita; $\mathrm{ESCAV}(\boldsymbol{\Delta})$ : preparo com escarificador a partir do segundo ano e arado de aivecas em 1979, primeiro ano de cultivo; PDAV $(\diamond)$ : plantio direto a partir

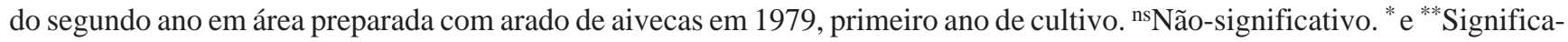
tivo a $5 \%$ e a $1 \%$ de probabilidade, respectivamente. 


\section{Conclusões}

1. Os sistemas de manejo influenciam as quantidades de nitrogênio nos grãos de milho de modo diferenciado.

2. Sob o sistema plantio direto ou sob cultivo mínimo, com escarificação, o milho apresenta, em geral, as maiores concentrações de nitrogênio nos grãos, nitrogênio total, nitrogênio derivado do fertilizante mineral e nitrogênio derivado do solo.

3. O modo de ação dos arados de discos e de aivecas, bem como a época de incorporação dos restos culturais, pré-plantio e pós-colheita, não causa diferenças nas quantidades acumuladas de nitrogênio, nitrogênio total e nitrogênio derivado do fertilizante mineral, nos grãos de milho.

\section{Agradecimento}

À Agência Internacional de Energia Nuclear (Contrato BRA - 10954), pelo fornecimento do fertilizante utilizado (enriquecido com ${ }^{15} \mathrm{~N}$ ).

\section{Referências}

ADÁMOLI, J.; MACEDO, J.; AZEVEDO, L.G.; MADEIRA NETO, J. Caracterização da região dos Cerrados. In: GOEDERT, W.J. Solos dos cerrados: tecnologias e estratégias de manejo. Planaltina: Embrapa-CPAC; São Paulo: Nobel, 1986. p.33-74.

ALFAIA, S.S. Destino de adubos nitrogenados marcados com ${ }^{15} \mathrm{~N}$ em amostras de dois solos da Amazônia Central. Revista Brasileira de Ciência do Solo, v.21, p.379-385, 1997.

CAMPOS, H. Estatística experimental não paramétrica. 3.ed. Piracicaba: ESALQ, 1979.343p.

COELHO, A.M.; FRANÇA, G.E.; BAHIA, A.E.C.; GUEDES, G.A.A. Balanço de nitrogênio $\left({ }^{15} \mathrm{~N}\right)$ em um Latossolo VermelhoEscuro, sob vegetação de Cerrado, cultivado com milho. Revista Brasileira de Ciência do Solo, v.15, p.187-193, 1991.

EMBRAPA. Centro Nacional de Pesquisa de Solos (Rio de Janeiro, RJ). Manual de métodos de análise de solos. 2.ed. Rio de Janeiro, 1997. $212 \mathrm{p}$.

GROVE, L.T.; RITCHEY, K.D.; NADERMAN JUNIOR, G.C. Nitrogen fertilization of maize on oxisol of the Cerrado of Brazil. Agronomy Journal, v.27, p.261-265, 1980.

JOKELA, W.E.; RANDALL, G.W. Fate of fertilizer nitrogen as affected by time and rate of application on corn. Soil Science Society of American Journal, v.61, p.1695-1703, 1997.

KITUR, B.K.; SMITH, M.S.; BLEVINS, R.L.; FRYE, W.W. Fate of ${ }^{15} \mathrm{~N}$ depleted ammonium nitrate applied to no-tillage and conventional tillage corn. Agronomy Journal, v.76, p.240-242, 1984.

KOSUGE, N.; SUHET, A.R.; BURLE, M.L.; LINHARES, N.W. Avaliação do potencial de suprimento de nitrogênio em um solo de
Cerrado. In: EMBRAPA. Centro de Pesquisa Agropecuária dos Cerrados (Planaltina, DF). Relatório técnico do projeto nipobrasileiro de cooperação em pesquisa agrícola nos Cerrados 1987/1992. Brasília, 1994. p.347-362.

LARA CABEZAS, W.A.R. Comportamento dos adubos nitrogenados em clima e solo de Cerrado. In: CURSO SOBRE ASPECTOS BÁSICOS DE FERTILIDADE E MICROBIOLOGIA DO SOLO SOB PLANTIO DIRETO, 1., Passo Fundo, 1998. Passo Fundo: Aldeia Norte, 1998. p.78-92.

MA, B.L.; DWYER, L.M. Nitrogen uptake and use of two contrasting maize hybrids differing in leaf senescence. Plant and Soil, v.199, p.283-291, 1998.

McCARTY, G.W.; MEISINGER, J.J.; JENNISKENS, F.M.M. Relationships between total-N, biomass-N and active- $\mathrm{N}$ in soil under different tillage and $\mathrm{N}$ fertilizer treatments. Soil Biology and Biochemistry, v.27, p.1245-1250, 1995.

OLIVEIRA, S.A. de. Métodos colorimétricos para determinação de nitrogênio em plantas. Pesquisa Agropecuária Brasileira, v.16, p.645-649, 1981.

PAUL, E.A.; CLARK, F.E. Soil microbiology and biochemistry. San Diego: Academic Press, 1989. 275p.

POWER, J.F.; PETERSON, G.A. Nitrogen transformations, utilization, and conservation as affected by fallow tillage method. Soil and Tillage Research, v.49, p.37-47, 1998.

RESCK, D.V.S. O plantio direto como alternativa de sistema de manejo e conservação do solo e da água na região dos Cerrados. In: CONGRESSO BRASILEIRO DE CIÊNCIA DO SOLO, 26, Rio de Janeiro, 1997. Anais. Rio de Janeiro: Embrapa-CNPS; SBCS, 1997. 1 CD-ROM.

SÁ, J.C. de M. Reciclagem de nutrientes e parâmetros para recomendação de adubação das culturas em sistemas de produção sob plantio direto. In: CURSO SOBRE ASPECTOS BÁSICOS DE FERTILIDADE E MICROBIOLOGIA DO SOLO SOB PLANTIO DIRETO, 1., Passo Fundo, 1998. Passo Fundo: Aldeia Norte, 1998. p.13-52.

SAMPAIO, E.V.S.B.; SALCEDO, I.H. Mineralização e absorção por milheto do nitrogênio do solo, da palha de milho- $\left({ }^{15} \mathrm{~N}\right)$ e da uréia$\left({ }^{15} \mathrm{~N}\right)$. Revista Brasileira de Ciência do Solo, v.17, p.423-429, 1993.

SUHET, A.R.; PERES, J.R.R.; VARGAS, M.A.T. Nitrogênio. In: GOEDERT, W.J. Solos dos Cerrados: tecnologias e estratégias de manejo. Planaltina: Embrapa-CPAC; São Paulo: Nobel, 1986. p.167202.

URQUIAGA, S. Eficiencia de la fertilización nitrogenada en los principales cultivos anuales. In: URQUIAGA, S.; ZAPATA, F. Manejo eficiente de la fertilización nitrogenada de cultivos anuales en América Latina y el Caribe. Porto Alegre: Gênese; Rio de Janeiro: Embrapa Agrobiologia, 2000. p.31-49.

URQUIAGA, S.; ZAPATA, F. Fertilización nitrogenada em sistemas de producción agrícola. In: URQUIAGA, S.; ZAPATA, F. Manejo eficiente de la fertilización nitrogenada de cultivos anuales en América Latina y el Caribe. Porto Alegre: Gênese; Rio de Janeiro: Embrapa Agrobiologia, 2000. p.77-88. 